\title{
Research on the Development and Prospect of Language Arts in the English Literature from the Renaissance Period
}

\author{
Wu Fei ${ }^{1}$ \\ ${ }^{1}$ TianJin Maritime College TianJin 300350 China
}

\begin{abstract}
In this paper, we conduct research on the development and prospect of language arts in the English literature from the renaissance period. The foreign culture enriches our knowledge and will enhance our wisdom. Literature is the most impressive place, work is not based in the real world, but the authors according to their needs and they want to express the meaning of the building of the world. European Renaissance movement were infected with Britain, the ancient Greek culture which was in English language and culture of the most obvious at this time. The influence of the movement push forwarded the development of the English literature. Our paper analyze the process in detail.
\end{abstract}

Keywords: Language Arts; English Literature; Renaissance Period; Development and Prospect.

\section{Introduction}

Reading English literature can be explained English network as an important way of culture and we can come into contact with the supporting surface of the deep culture. The English-speaking country culture of fundamental ideas, value judgment, two people often use perspective, and the criticism of these perspectives. English literature is the era of the aesthetic expression of life, is a product of the English-speaking countries people's creative use of the English language. Its noon rich expressive force and unique charm in English writers get the play of incisively and vividly. Reading good English literature can feel the beauty of English language. The foreign culture enriches our knowledge and will enhance our wisdom. Literature is the most impressive place, work is not based in the real world, but the authors according to their needs and they want to express the meaning of the building of the world and in this world that can be a lot of unexpected happens there will be many unexpected, understandable situations. The author to express these things through English language arts, can tell the background of the incident, rendering the characters in the literary mood, shaping a variety of personalities of the characters, the characters of thoughts, use these tactics to achieve the purpose of the author want to express, and to meet people in real life with or without desire, carrying people's happiness and sadness. Literature expresses not only the words and emotions. The author put his feelings into the works and the works seem more real, when readers in reading are that much more fascinating. In these literary works showed whether happy or sad to be able to express through words, display its unique in the literary works [1]. Therefore, without the piece of literary work is no emotion and meaningless, no literature is ignoring the author is not existed alone.

Important influence of English language and culture of the ancient Greek myth, the 16th century, European Renaissance movement were infected with Britain, the ancient Greek culture which was in English language and culture of the most obvious at this time. Rendering and wide spread of literary work experience for many years, from the ancient Greek classical mythology in the related content of communicative language category, and to enrich the expressive force of the English language, in different areas of the language also makes people overwhelmed. The concept of the ancient Greek culture is influenced 
by the western civilization and involved in the category of English language and literature, English language and literature major in colleges and universities courses in ancient Greek mythology content is very necessary. Content before and after the structure of the ancient Greek myth has a complete full, very coherent, sometimes difficult to use the simple language to the background knowledge are summarized. Wings god horse in ancient Greek mythology are flying in the heaven and earth, omnipotent great scholar, mercury as Zeus and the general messenger of the gods, management and business in areas such as transportation, the nimble, agile and famous everywhere. Often appears in the image is not only in literary works, in other art fields are often the subject of the borrowing. Shakespeare used the image of the better known, detailed describes the prince Henry lithe, to show people a three-dimensional image of the strong. Legend muse with bill and daughters challenges will singing, helicon smell this song is very happy and increased, god cangue cells after Sotheby's feet to live here and spring, generation poets after drinking can get inspiration to write. It could be reflected from the literature review that the development of the culture influence the English language.

In ELD instruction, language is the primary objective and content is secondary. In sheltered instruction, content is primary and language is secondary.

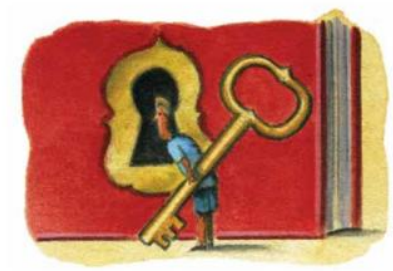

Figure1. The Principles of Language Arts in the English Literature

In this paper, we conduct research on the development and prospect of language arts in the English literature from the renaissance period. In the above figure, we illustrate the comment of the linguists for the language development. English literature from the before Christ began to appear, the literary classics are until now still thrives, scholars around the world have become one of the research object, which is very important to literary language art. The creation of literary works is a kind of language art, and study the art of language for a deep understanding of English literature, appreciation of literary works has very important significance which will be introduced later.

\section{The Proposed Perspective and Methodology}

The Principles of the Renaissance Period. In the primitive nature of social conditions to explore the ancient Greek mythology between people and society, between man and god, the relationship between attention problems are essential. Because of their feelings and eternal theme in humans, to explain the common humanity well and because of its depth and penetration, the ancient Greek classical myth has a profound connotation which can transcend time and space, show the unique artistic charm. Languages to philosophers before did not distinguish between the philosophy of daily usage and usage of words, often think of when philosophical vocabulary use common words and make them difficult and need to use everyday language to explain. Language analysis can provide this kind of explanation. Second, many philosophical problems and we did not differentiate between language and of language, language analysis is the best way to avoid these problems; Third, the language can't do everything, but some things hard to performance was not a question of the thing itself, but we failed to find out the structure of language [2]. The traditional method also to think language is a kind of philosophy, it requires by looking at language to reveal the essence of things.

Speculative grammarian on universal grammar theory and explore, based on the number of corpora in both languages corpus is very limited, thus the rationality of its theoretical criticism from later scholars. Because, the broader language experience has shown that every language has different from other language rules of grammatical structure and semantic 
category, and these rules and categories are associated with its features. On the other hand, language and culture of different nationalities, living in a different world and the difference of the world with the grammatical structure and semantic structure difference is associated. In the field of linguistics, this happened during the period of some seemingly separation and, in fact is a contact sport. First is the decline of Latin as an international academic language, at the same time, other European countries outside Europe countries and even national language or dialect of the emergence and by understanding and learning, then there is a variety of language research findings, including the language syntax and from these events and movement, the empirical shallow thinkers see speculative syntax [3].

Common language solutions could be the earliest in the modern western civilization language planning and language engineering plan. Now, it seems, no matter in the language of engineering and technical sense or in language communication function sense, the common language of any design and plane is very naive and simple. Therefore, the significance of these solutions is not the pioneering language planning and the engineering concepts. But in these scholars through their work expresses a kind of human thought and knowledge common symbolic rationalism philosophy.

The Development of the English Literature. Last century, western literature is probably can be divided into two lines one is from modernism to now after continuous development and change of realism literature and another continuing development of realism literature. The strong vitality and development of realism literature has a great influence on last century world literature. It reflects highlighted the development and changes of a century of the spirit of the society. Realism literature has a long history in the last century and a new development and changes which absorbed the manifestation of each genre. They retain the basic characteristics of realism literature and pay more attention to the plot structure and the performance of the language style of complete and unified. And use literature image reflects the realistic problems in the society and life, at the same time, it also had further development in the narrative form and deepen widely used and absorb the modernism and postmodernism art gimmick, make of the last century's realism literature presents a rich and colorful boom. Nowadays the society using a writing style in literary creation is impossible. Diversified creation became a kind of creative ideas and writing direction. Although modernism and realism is a big gap, but there are also common [4]. Most of them are sometimes-complex mix-and-match, we have the inseparable connection, most of the postmodern writers have been influenced by modern and modern writers often use related postmodern expressional technique. In the last century the basic characteristics of western literature is diversity. Western scholars think that: according to the relative and absolute doctrine is the premise of multivariate exists. Not have the strict limits on pluralism, allowing a variety of ideas to communicate, make their own understanding of the interpretation, and more fully closed to avoid each other. At the end of the last century, the western cultural absolutism become the target of people, the writers have started a new exploration of the country. At this moment all over the world in a new starting point, the human culture emerged diversified development momentum, cultural exchanges and dialogue has become the real focus issue.

The United States as a British colony and modern large immigrant country, the language used is English, but affected by the local Indian culture and other countries and regions of immigrants, grew out of the barriers of British English. At the same time, the United States as a newborn capitalist republic of the almost no problems left over by history on politics, economy and culture is a new body. These reflected in language use aspects of literary criticism, literary critics do not need to carefully, 
appear very make public, and personality, to some extent, reflects the national cultural atmosphere of freedom, democracy. British and American literary criticism is a literary theory to study the practice of the British and American literature activities, aims to study the inherent law of British and American literature and provide reference for British and American literature. The form is varied, according to the form of literary works can be divided into prose, novels comment, poetry, drama comment, and so on. For the readers to better grasp and understanding of literature theme, improve the ability of literature reading and appreciation has a very important role and at the same time, its literature creators to master the inherent law of literary creation and understand the bystanders suggestion and opinion, to further improve and processing work also has an extremely important role. Since the 20th century, due to the prosperous development of British and American literature and American literature reviews are also vigorously forward, into the era of glory. Because of the general influence of various thoughts, especially the influence of structuralism and post-colonial, British and American literature review also in the event of a profound change.

In Greek mythology and the relationship between the British and American literature is the source and flow of the relationship between inheritance and development. British and American literature has a long development under the influence of Greek mythology, to say the Greek mythology as the process of forming, development and outbreak of British and American literature laid a solid literature foundation. Ancient Greek poet thanks the poems are in the process of the development of Greek mythology system, such as to give an important contribution to the literature. The British and American literature and draw nutrition from these cultural treasures. In many British and American writers works can be seen the Greek astronomer and the shadow of the Greek myth.

The Prospect of Language Arts in the English Literature. Post-modernism ideological trend in the 21 st century will still continue, literary form of the experiment will continue, because the form for the work is very important, its importance lies in helping to unlock the silence of the material, and thus makes the text. A tune in a different Musical Instruments playing the effect will be different, the same content, different literary form, the aesthetic fast optimum is different also, to be able to open the material will be in the form of precipitation in the form of literature. But, for beyond the experimental literature of understanding ability, its development will be very limited because such works hard to be appreciated, the reader to form their own survival difficult to enter the field, so it is difficult to form work. In the future will also to generally focus on the people in these aspects, the orientation of "existence" continue to deepen and rich. (1) Literary subject pluralism. 21st century western literature presents the diversification, such as gay literature, postcolonial literature, ecological literature, detective literature and fantasy literature, war literature and suffering, and so on will emerge in endlessly which will meet the different readers' aesthetic interest. These challenges the traditional literature value, challenge essentialism, the grand narrative of literature were replaced by a small narrative, vulnerable groups are focused on, "the other" attention, be repositioned, the literature of different ethnic groups and individual life feeling to care for this in person. (2) The mix of literary elements. With the advent of the era of globalization, literature is not satisfied with a single cultural elements, when a writer across languages, across the nation, across the country's educated, their literary works are often mix of heterogeneous elements, this kind of literary works and rich multiple charm. (3) The popularity of the classic literature. Rheological within the scope of the globalization, literature 
have become inevitable, which undergoes various filtering and rewrite, often with the target language context is closely related to the ideology and culture of the country, at the same time, the adaptation of writers in the creation, may also join the life of their own sense of the condition which is also for this reason, after the adaptation of work to various variations produced as described above.

\section{Conclusion}

In this paper, we conduct research on the development and prospect of language arts in the English literature from the renaissance period. With the further development of the culture time, we will see everything into a literary and artistic works. The combination of music, image and the language comprehensive makes literary works more perfect. Fully embodies the advantages of technological progress. The development of the 21 st century, the world shows that tend to be out of the global integration. The popularity of the network changed people's way of life, fully embodies the world there is no distance, everyone can understand what is happening at any time which also changed the young generation of literary expression, also changed my literary ideas. We firmly believe that with the rapid development of the literature, the English and language will get rapid expansion.

\section{References}

[1] Peter W. van Rijn, E. Aurora Graf, Paul Deane, et al. Empirical recovery of argumentation learning progressions in scenario-based assessments of English language arts[J].

[2] Soter A. Incorporating the metaphors of daily life into the English/language arts curriculum[J]. Literacy Learning the Middle Years, 2014, 22(1).

[3] Moore J P. Explicit and Meaningful: An exploration of linguistic tools for supporting ELLs' reading and analytic writing in the English Language Arts[J]. Dissertations \& Theses-Gradworks.

[4] Myhill D, Watson A. The role of grammar in the writing curriculum: A review of the literature $[\mathrm{J}]$. Child Language Teaching \& Therapy, 2014, 30(1):41-62. 